from each descent of the piston not being felt in the shamber itself. In most establishments the air is pumped directly into the bath, the supply pipe entering near the floor. In many, as at Johannisberg, Zurich, and Berlin, the pump is arranged to rarefy, as well as to condense the air, and this is done by a modification of the valves, or rather by reversing their positions. It is much to be regretted that some arrangement of this sort was not made here, but the initial cost, already very great, was an obstacle.

A receiver for filtering the air from the dust and mechanical impurity is often inserted between the compressor and the air-chamber. It generally consists of a small cylinder or box containin layers of cotton-wool, through which the inlet-pipe passes immediately before its entrance into the bath. In hot weather this cylinder may be partially filled with ice, to reduce the temperature of the air. If this receiver be large enough, it also answers the purpose of a reservoir, and converts the puffs of air into an even current.

On page 771 is a drawing of the Brompton Hospital compressed airbath, kindly made for me by Mr. Blake, the manager of Messrs. Haden and Sons' works, who were the contractors. It consists of three parts ; the engine (A), the receiver (B), and the air-chamber (C). $A$ includes a steam-engine $\mathrm{D}$, which, by means of a fly-wheel and erank, works a second engine, $\mathbf{E}$, in another and separate compartment, $F$. $E$ is the air-compressing engine, with a cylinder containing an inlet-hole and an outlet-hole, and in this cylinder works the piston $\mathrm{H}$, the plate of which is perforated by diaphragm-valves, which are not here shown, and which close during the descent of the piston and open during its ascent. The air from outside enters the compartment $F$ through the inlet $G$, and follows the course indicated by the arrows. Entering the air-cylinder, it is driven forward by the piston, through the pipe, $I$, into the receiver $\mathrm{B}$, containing layers of cottonwool, $w$, into the air-chamber. Both $I$ and $J$ contain valves to prevent a return current. The air leaves the bath by an outlet-pipe in the roof, which is always open, the strength of the current through it depending on the rate at which the engine works. $M$ is a safetyvalve which opens wide and blows a whistle, when the full pressure of $10 \mathrm{lbs}$. is reached. $\mathrm{L}$ is a glass spyhole, through which the inmates can be watched. $\mathrm{N}$ is an airtight cupboard, fitted with double bolts to adjust the pressure, and to enable food and messages, and, if necessary, medicines, to be passed in. Apparatus to regulate the escape of air, which can be worked both from within or outside the bath, complete the chamber, which is lit from without by stout plateglass windows, and fitted with a strong iron door. The air can be changed about five times in the two hours.

The chamber itself in all cases is furnished with chairs and tables, a water-bottle and glasses to meet the thirst and uncomfortable throat-symptoms, which often accompany increase of pressure; also with a pressure-gauge to record the variations, and a thermometer and a wet and dry bulb apparatus.

Care should be taken that the air be supplied from a pure source, fik $\theta$ an open space, as a garden or court-yard, away from all machinery or drainage. It should be filtered through cotton-wool, and the temperature regulated as far as is possible. In some baths there is an apparatus for heating the air, but in our own the temperature has generally been too high rather than too low, and in the hot weather it was found necessary to pass the air through an ice-box, to reduce it sufficiently for the bath purposes. The dryness is seldom a trouble, and a saucer of water on the table will correct it by evaporation.

'In some of the German baths, in winter, the temperature falls so low that it has been found necessary to pump in air specially heated The amount of compression used for medical purposes is small, and varies from $\frac{1}{2}$ to $1 \frac{1}{2}$ atmospheres. Here we do not exceed $10 \mathrm{lbs}$., that is, about two-thirds of an atmosphere, which is ample for the treatment of lung-diseases, and even before the pressure is reached complaints are made of headaches; as a rule, a pressure of $7 \frac{1}{2}$ to $9 \mathrm{lbs}$. is sufficient to produce the ends we have in view.

$\hat{A}$ bath, or sitting, generally occupies two hours; half an hour being spent in gradually increasing the pressure, which is maintained for whole hour at the maximum, and half an hour in gradually decreasing it to the minimum. The rate of increase or decrease should be $1 \mathrm{lb}$. in two or three minutes. The number of baths to be given must depend on the case, but at least a dozen are required to produce permanent improvement, and sometimes 30,40 , or even 100 , are eedful.

During compression the air increases in temperature, and this is, of course, more the case when the bath is occupied. During reduction of pressure there is sometimes a slight fall; but what is most marked is the deposition of moisture, which is seen on the glass windows during this process, and which, whon the door is opened, bften amounts to a mist in the chamber. This is, of course, due to the quantity of moisture which the air was capable of holding in suspension at a high pressure being diminished when that pressure is reduced. The chief points to be aimed at in the management of compressed air-baths are :-

1. To increase and reduce pressure as gradually as possible.

2. To keep the temperature of the bath within reasonable limits, say between $60^{\circ} \mathrm{Fahr}$, and $65^{\circ} \mathrm{Fahr}$.

3. While increasing or maintaining the pressure, to provide for the escape of the used up and contaminated air.

4. If bad symptoms have arisen from increase or decrease of pressure, to reverse the process at once.

\section{ON SOME POINTS IN THE ETIOLOGY OF PHTHISIS.} Read before the Medical Society of London.

BY I. BURNEY YEO, M.D., F.R.C.P., Physician to King's College Hospital.

I Do not propose in this short paper to travel over the whole of the ground involved in an inquiry into the etiology of phthisis; but I wish to take this opportunity of examining, a little in detail, certain statements that have been made, and certain criticisms that have been put forward, in recent contributions to this most important discussion.

I shall offer no apology for bringing this subject before this Society for, until the truth, whatever it may prove to be, has been firmly established and generally admitted, as to the causation of a disease so widely spread and so fatal as phthisis, frequent and repeated inquiry becomes our duty. More especially is this the case, since the discovery by Koch of the bacillus of tubercle has lent additional interest and impetus to the inquiry whether phthisis does, or does not, originate in the direct or indirect communication of the exciting cause of the disease from one person to another.

The important practical question of prophylaxis is intimately associated with this discussion ; and it is, therefore, urgently incumbent upon us to endeavour to ascertain clearly what is the truth in this respect.

Some of the criticisms to which I shall have to refer have had reference to the Report of the Collective Investigation Committee of the British Medical Association, on the Communicability of Phthisis; and, althongh the whole of the subcommittee entrusted with that inquiry accepted the responsibility of that report, I, as its author, am more directly concerned in defending it from misinterpretation.

One of the most considerable and interesting contributions to the inquiry into the etiology of phthisis that we have had of late years, is to be found in Dr. Andrew's Lumleian Lectures, delivered last year before the College of Physicians. I need not say that the argument which runs through these lectures is stated with great ability and ingenuity; that they are replete with interesting observations and important illustrations; and yet; I am forced to contend that the conclusion arrived at therein is altogether erroneous. As the authority of their author is so deservedly great, and as the occasion which called forth the expression of his opinion was also authoritative and influential, it becomes all the more important that we should examine in detail the doctrines thus set before the profession.

First of all, it is necessary to keep in our minds Dr. Andrew's admissions. "I am well content," he says, " to accept the bacillus of Koch as the essential cause of phthisis, and that, too, in the extreme form in which the doctrine has been stated to me by my colleague, Dr. Klein-namely, 'no tubercle without bacillus, no bacillus without tubercle ;" and, subsequently, he shows with much force how "the hypothesis of a specific organism, present in all cases of phthisis, as its proximate exciting cause, clears up and reconciles the obscurities and contradictions which exist in every branch of the subject."

Having made this admission, the whole of his subsequent argument rests on the following assumption : that the bacillus of tubercle has an "independent" as well as a "parasitical " phase of existence; and the truth of this assumption has to bear the whole weight of the conclusion, that phthisis is neither directly nor indirectly communicable !

This argument may be thus briefly stated. Phthisis is always caused by a specific micro-organism, without which there can be no phthisis ; but this organism can and does only give rise to phthisis in man and animals, when it exists independently of any "host," that s, when it is non-parasitic.

The author of this argument does not-seem the least embar rassed by the consideration, that the hypothesis of the "independent" existence 
of the "s "bacillus of tubercle".! has not a single demonstrated fact to rest upon; but he considers it justitied by an/ ingenious; bnt, to my mind, a wholly inconclusive and greatly strained analogy between phthisis and ague.

Let us consider this point somewhat carefulfy, for it is the essential basis of the whole argument contrined in those lectures.

The bacillus tuberculosis, it is maintained, must be in an "independent" and "non-parasitic" phase of existence, in order to be capable of causing phthisis in men; that is to say, in a phase of existence in which it has never yet been known to exist. For we have no knowledge whatever of the bacillus of tubercle, except as a parasite.

Dr. Andrew has not stated his argument quite in this direct and bare manner; had he done so, I cannot help thinking he would have been a little startled at it himself. For, if he were to admit that the parasitic bacillus is capable of engendering phthisis in the human subject (apart from inoculation-experiments), then his argument admits another remarkable development, which I will venture to give it. It would run thus.

There is a bacillus of tubercle found existing as a parasite in certain men and animals ; it is capable, in its parasitic form, of exciting phthisis in other men and animals, yet it never does so ; for, when it does so, it is always in an "independent phase" of existence. In other words, an infective organism, as we know it, see it, and eramine it, never, in the ordinary conditions of life, displays those qualities which experiment has demonstrated it to possess ; but it can only do so when it exists in another and "independent" phase, in which phase we do not know it, and of the existence of which we have not one particle of proof.

Surely this argument, asking us to give up the known for the unknown, the "bird in the hand" for "none in the bush," makes a very severe and unusual demand upon us ; for we know that the organism of tubercle passes into the air from the breath of persons affected with phthisis ; we know. that it is expectorated in the sputa of phthisical patients, who.contribute one-seventh of the total mortality, so widely and universally is this disease diffused (how unlike ague); and we know that, in both these forms, it is virulent and active ; yet we are invited to disregard entirely these obvious known agencies for the diffusion of the tubercle-bacillus, or to regard it, in this form, as absolutely harmless, while, at the same time, we are asked to admit that this infective micro-organism can only harm the human race when it occurs in an "independent," "non-parasitic" phase of existence, which phase is wholly imaginary, and without one demonstrated fact to support it.

And here I must remind you that, if it be admitted that one single case of phthisis has been or can be caused by an infective organism which has pre-existed in another person, the whole case of the noncontagionists is surrendered; for then the question is no longer one of communicability or non-communicability, but simply one of degree of communicability, a wholly different question. I cannot insist too strongly on this, becanse it applies to a great deal of loose unprecise thinking, which is far too common amongst us. For my own part, I am disposed to argue simply for the fact of communicability ; the question of the degree of communicability is another matter. But I utterly decline to accept an imaginary bacillus of supposed "independent" origin, as the cause of phthisis, in the place of this now well known, widely diffused parasitic bacillus ; I, however, accept the bacillus as the true exciting cause of all tuberculous phthisis as fully as anyone can, and I carry this acceptance to its logical consequencea little startling as it may at first sound-namely; that all tubercular phthisis is the result of direct or indirect communication. The only escape from this conclusion is in Dr. Andretw's hypothesis of a nonparasitic tubercle-bacillus. If this exist, seeing how generally diffused a disease phthisis is (utterly unlike ague in this respect), there ought to be no difficulty in finding it. Every human being is, every moment of his life, making an experiment on the surrounding atmosphere, aspirating the air around him into his air-passages, with the suspended particlee it contains ; yet this organism is never found in the secretions of the air-passages, although sought for under very likely circumstances, unless in the subjects of phthisis. Surely, if it existed in the air as an "independent" organism, as widely diffused as phthisis itself is diffused, we should find it in the secretions from the air-passages in some of the subjects of simple catarrhal affections ; but it never is found under such circumstances, and its presence in the sputa is certainly diagnostic of phthisis ; its presence in the expectoration would lose its diagnostic value, if its presence in the air were as common and diffused as is the presence of phthisis amongst us.

This brings me to the consideration of an argument which was used by Dr. Douglas Powell in the discussion on the causes of phthisis at the meeting of the British. Medical Association at Belfast, and which ine appears to think, negatives the idea that the infection of phthisis is communicable. 'He refers to his eight years' work in the out-patient rooms of the Brompton Hospital, and he seems to think it remarkable or significant that phthisis was not communicated either to the nonphthisical patients or to the physicians there. He says: "I have watched cases of emphysema, of chronic bronchitis, of asthme, $\therefore$ of chest-rickets, of cardiac disease, etc., for months, some of them, at intervals, for years, and they have not become phthisical. Now these people have been, for two or three hours at a stretch, exposed to the 'virulent' atmosphere of a crowded waiting-room, nine-tenths of the oceupants of which have been phthisical. With a courage, perhaps begotten of ignorance, I have myself sat for three or tour hours twice a week for eight years practically in the midst of these people; taking my luncheon in the sarre room, and washing down the bacilli with my coffee."

Now I have as good, or even a better, right to speak of these conditions as Dr. Powell ; for, instead of his eight years, I spent ten years in the same room, and often for four hours at a time, seeing in these ten years over 27,000 separate patients ; and I maintain that his statement has a tone of exaggeration and want of precision about it which ought not to be imported into a discussion of this kind. He says that nine-tenths of these out-patients were phthisical. I cannot imagine that the patients of Dr. Powell could have differed in character from my own; and my out-patients at Brompton were not one. half nor one-third of them phthisical; often, I should say, not onefifth. There were always an immense majority of dyspeptics, of cases of emphysema and chronic bronchial catarrh, of anæmia with some emaciation, and a considerable number of cardiac cases.

Then he infers that, if any of these out-patients had acquired phthisis in these waiting-rooms, he must have. known it. I cannot see why. I have no knowledge whatever whether any of my 27,000 patients either acquired phthisis in the Brompton out-patient room, or conveyed it to others thers or elsewhere. When one has to see 200 patients in an afternoon, there is but little time to spare for inquiring into difficult questions of causation. I do not see how one particle of value can attach to such a statementin an avowedly nice and difficult investigation such as this is.

The rooms to which he refers were by no meansill-ventilated; they were well supplied with windows opening upon a large garden or lawn, and free circulation was permitted through a large passage, opening also into the garden. The room occupied by the physician had three swinging doors in it, and a window also opening into the garden, through which I used constantly to let in abundance of air and sunlight. Many medical visitors who attended my practice used to speak highly of the comfortable arrangements there for seeing patients.

There is a Freneh maxim to the effect that everything that is exaggerated is insignificant; and I think that maxim applies to this kind of argument. But what shall we say of his "washing down the bacilli" with his coffee? I must express my regret that anyone speaking with authority should have treated the question of the diffusion of the bacillus of tubercle so lightly. If it were intended to actually express a belief that the bacillus of tubercle was a harmless thing, and that numbers of them actually were passing into Dr. Powell's stomach with his lunch, then I must insist that there is no evidence whatever to support such a statement.

For what are the facts that bave been ascertained and demonstrated in the Brompton Hospital itself? In the case of nonphthisical, catarrhal patients, aspirating the air of the hospital into their air-passages every moment, and frequently expectorating the secretion from their air-passages, in no instance has a single specimen of the bacillus tuberculosis been found in such expectoration; and yet Dr. Powell has suggested that they commonly found their way down his œsophagus. This suggestion seems to be made with the object of discrediting or throwing ridicule on the evidence and the arguments that have been advanced in favour of the communicability of phthisis.

Now, it appears to be a demonstrated fact, as I have shown, that the bacillus of tubercle is not commonly or widely diffused through the air, even in a consumption-hospital. How ought we to regard this fact Simply as a part of the life-history of phthisis. What is its relation to the question of the communicability of phthisis? It does not affect the fact of communicability in any way, but it is very important when we come to consider the degree of communicability, or the laws of the communicability of phthisis. Dr. H. Weber, on this head, remarks justly. "The air we inhale, perhaps, does not so often contain the fully developed bacillus as is supposed by many people, for this microbe does not thrive in the air at the usual temperature, but requires, according 


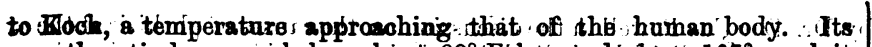
growth entirely ceases below about $82^{\circ} /$ F bhr., dnd above 107 , and it thrives best at about $98^{\circ}$ t to $100^{\circ}$ 'Fahr., while other pathogenic organ. isms have a mach wider field; the anthrax-bacillus grows luxuriantly between $67^{\circ}$ and $74^{\circ}$, and up to $110^{\circ} \mathrm{Fahr}$. A further point against the spread of the tubercle-bacillus ont of the animal body is, that it does not form spores in thie air, while the anthrax-bacillus does. Another pecaliarity in the life of the former is that it grows slowly, that it requines as many days for its development as the anthrax-bacillus requires hours:"

These considecations obviously greatly diminish the risk of commarication; though they by no means render it impossible.;

And here I should like to mention a case that was,' some years ago, nnder my own care in the Brompton Hospital. It was a very remarkable one, and was probably one of those cases that we are told never oceur in that hospital.

I may say, once for all, that I regard it as merely trifling with this subject to tell us how many cooks, and dispensers, and kitchenmaids, and porters, and secretaries, have officiated in the Brompton Hospital, and have not died of phthisis. We all know that, in this country at any rate, phthisis is not contagious in that.degree; but, possessing, as we do, a priori grounds for believing phthisis to be spread by communication, we want to ascertain the nature and degree of that communication, and the laws that govern it. We want that question dealt with seriously, honestly, and without prejudice.

In October 1877, a labouring man, 49 years of age, with a good family-history, but a tendency to rheumatism and gout, came under my care as an out-patient at the Brompton Hospital. He was found to be suffering with aneurysm of the thoracic aorta, and, on laryngoscopic examination, he was found also to have a large pedunculated papillomatous growth in the larynx. I took him into King's College Hospital, and there Sir Joseph Lister removed this and other smaller growths, and with them the true and false vocal cords, and a considerable portion of the mucous membrane lining the larynx. The man made an excellent recovery, and expressed himself as more comfortable than he had been for nine years.

In February 1878, we (Sir Joseph. Lister and myself) brought this case before the Clinical Society, and showed the patient there, as there were points of interest in the case with which we are not now concerned. One, however, was that he was able to speak audibly and articulately without vocal cords.

By the kindness of my colleague Dr. Tatham, I subsequently received this patient into the Brompton Hospital, for convenience of laryngoscopic examination. The case being almost an unique one, he was repeatedly examined by those who took an interest in larrngology, Dr. Semon, Dr. Poore, Mr. Lennox Browne, and many others. He was, therefore, frequently making deep forced inspirations, with his mouth widely opened, and his larynx devoid of its usual protecting folds of mucous membrane, a state of things very favourable to the aspiration of floating atmospheric germs into the air-passages. Now, what happened? After some time, he began to have a troublesome cough, which we naturally thought due to aneurysmal pressure; then he had a small hæmorrhage, which we concluded might be from a slight crack in the aneurysmal sac; then he had another hæmorrhage, and died.

At: the necropsy, to our great surprise, we found the aneurysmal walls intact, and that the fatal hæmorrhage had been from a small carity in the apex of the right lung, which was the seat of phthisical diserse.

This happened before the discovery of the bacillus; and, as the eye only sees what it brings with it the power of seeing, so the mind only thinks as it is inclined to think. At that time, I was a strong anticontagionist, and I did not dream of referring this patient's phthisis to communication ; indeed, it was only a few months ago that the case came forcibly back to my mind as a possible - I do not say a certain-instance of communication. I did not report it to the Collective Investigation Committee, for it was not till some time after the publication of that report that the case recurred to my mind; and what happened to me with regard to this case may have happened to others with regard to cases that they have seen, but not realised.

Since my mind has been alive to the possibility of communication, I find I obtain evidence in support of this view which. I never obtained before-probably because I never sought for it; and sometimes the evidence comes, as it were, by accident.

Not long ago, I saw a gentleman with phthisis, who lived a healthy out-of-door country life, with no family-predisposition. I had attemded him before for some loss of muscular power, after an attack of diphtheria. I had no thought of referring his phthisis to any pos. sible communication; but, when it became a question of change of climate, I receitred a letter from one of ' his reldtitès, begging that I would not send him away " from his poor consumptive wife."

Not long afterwards, I saw, in consultation, a fine foung Scotch girl, with phthisis, of a very healthy long-lived family; bnd, when the question was asked, Why had she became phthisical? on making full inquiry, it was found that, some few months before, she had bein given a bedroom which had just been quitted by a maid-servant with phthisis.

Within the last. week or two, a patient of mine, a native of Silesia, died of phthisis of a very curious type. She had been under my observation for two or three years ; and it was only. a few days before her death, when the husband was asking me how she could possibly have acquired -phthisis, that he told me of the fact that, three years before, she had assiduously nursed a friend who died of that disease.

I mention' these as instances of the casual way in which evidence of possible communication crops up, if we keep our minds open to the reception of such testimony.

I must now refer to some criticisms of the Report of the Collective Investigation Committee on the Communicability of Phthisis.

Dr. Powell, in the paper I have already quoted, contents himself by merely saying that "the results of their inquiries are as yet highly force and finality. of the coffee-argument, but they at least merit some examination.

Let me quote, as a set-off to this estimate of that report, one by Dr. Wm. Roberts of Manchester. "I think," he says, "no candid person can read this report, and the detailed evidence on which it is based, without coming to this practically important conclusion, that no healthy person should be permitted to occupy the same bed with a sufferer from pulmonary. consumption, and that no person with a hereditary predisposition to tuberculous disease should be allowed to have continued and intimate personal contact with a phthisical patient; and I cannot help adding that a great responsibility would; in my opinion, be incurred by a medical man knowing this evidence, no matter what his theoretical opinions may be, who would permit such cohabitation and close personal contact."

Next, with regard to Dr. Andrew's criticism of that report. "There is," he says, "one fault in the mode in whieh the investigation was conducted, which must have had considerable influence on the result. In the questions circulated, the Committee ask for affirmative cases only; notwithstanding this, they received several answers containing cases which appear to disprove the contagiousness of phthisis. The number of these would have doubtless been much larger, had they been specially asked for; and, in any future inquiry, it is to be hoped that this will be done."

This criticism shows that Dr. Andrew, as well as others who have criticised this report, did not follow the course of the inquiry with that interest which those who took part in it may be supposed to have done; for in the British Medical Journal, the medium through which all our communications were made, of March 3rd, 1883, together: with the second issue of the form of inquiry, the following in. struction was published.

"The affirmative answers naturally attract the 'greatest interest; but negative replies, with regard to cases which have been surrounded by circumstances which might have favoured communication, are, it need scarcely be said, of almost equal value ; while simple negatives have also their importance, as affording evidence, at any rate, of the relative frequency with which cases, supposed to awe their origin to infection, have been observed."

It was this request that brought us the very reports to which $\mathrm{Dr}$. Andrew refers; and if "fault" exists on this point, it is not on our side; and Dr. Andrew's suggestion that "if negative facts and opinions had been asked for, the majority might have passed to the other side " is wholly without foundation.

I must be excused for saying that I think these hasty and incon. siderate criticisms of a report which cost so much thought and labour, these mistakes as to matters of fact, which a very little inquiry would have prevented, are the reverse of praiseworthy.

Dr. Andrew next objects that we gave too literal a meaning to the simple word "No." "A friend tells me," he says, "that his "no" was a very active little word indeed, by which he meant to convey. not merely that he had seen no cases of contagion; but that he had noted its absence in cases where, if present, it must have manifested itself.'

Conld we possibly separate the "noes". which simply meant "no": from "noes" which, like Lord Burghleigh's celebrated shake of the head, meant so mach as this? It is true that some of the simple 
"noes" reached us very much underlined; they looked to us more than adive, violent even. "Whandedithen with certain caution,

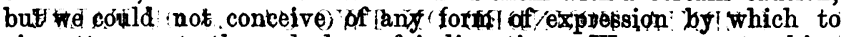
give utteranoe to these fashos (of ipdignation, We were not asking for indignation or activity, wo were asking for facts and réásons, and where we found them we reproduced them, whatever their tendency.

Next, with regard to the criticioms sthat have i been offered on the cases of supposed commanication observed between husbands and wives. It has been assumed by some that these were accidental cases, unattended by any. special circumstances ; but, in the great majority, this certainly was not the case, for the reporters were especially careful to distinguish between cases which might be regarded as accidental coincidences, which they had not thought of reporting, and the reported :cases ! which had occurred under circumstances af fording special grounds for inferring communication. .: To suppose that cases of merely accidental incidence of phthisis, in both husband and wife, had been reported as cases of communication, was to refuse creditfor ${ }^{1}$ ordiniary sagacity and reflection to a body of really very careful and intelligent observers.

It was of the commonest occurrence to meet in the reports with a statement of this kind. "Of course, I have seen many instances of both husband and wife succumbing to phthisis, but the following calse (or cases) struck me, at the time, as affording an instance of probable communication " then would follow the case or cases published. It was impossible to give all these remarks in the limited space alloted to us ; but, as I have already said, the observers might have been credited with suoh elementary discrimination.

Dr. Andrew says, "It is a little remarkable that this exceedingly doubtful class of zases (husbands and wives) should furnish no fewer than 192 out of 261 affirmative observations." But it is more remarkable that Dr. Andrew should think this remarkable. If phthisis be communicable: only under certain special conditions, one of those being close personal intimacy, as, for instance, inhaling the breath of the infected person at close quarters, is it in the very slightest degree remsirkable that the vast majority of instances should be found to occur in the case of husband and wife? I do not see how it could possibly: be otherwise.

Again, it is important to notice how Dr. Andrew, from his standpoint; criticises one of the most remarkabld of. the instances of apparent communication reported.

Miss R., aged 48, a dressmaker, living in rather a lonely cottage at C., Bedfordshire, had three apprentices, young girls of from 17 to 19 years of age, not related, from three adjoining villages, who took it in turn to remain in the house and sleep with her, each one for a week at a time. During their apprenticeship, Miss R. was taken with phthisis, of which she died. In less than two years afterwards, all three apprentices died of phthisis, although, in the family-history of each, na trace of phthisis existed, and the parents, brothers, and isisters of two of them are alive and well at the present time.

"Here, ayain," he says, "there are various little difficulties in the way of explanation by contagion. This must have been most virulent in the case of Miss R., and yet no harm came to any of the friends of the unfortunate apprentices." But why, I would ask, should the contagion be said to be "most virulent" in this person more than in anyiother where the conditions were similar?: Why more virulent than in all the cases reported of husband and wife? Were we a polygamous people, we should have the conditions related in this caso common amongst husbands and wives. If three persons be ill with soarlet ferer, and one communicate it to three others, another to two others, and the third to no one, should we infer, on that account alone that the first case was more virulent than the second or the third? Surely we should content ourselves with the conclusion that the conditions were more favourable to communication in the first case than in the third.' Why, again, should these apprentices necessarily communicicate phthisis to their relatives?

Dr. Andrew had previously argued fully, ably, and conclusively for the necessity of the existence of predisposing factors in the causation of phthisis, and these factors may have been absent in the relatives of these apprentices, and they probably did not live with them on the same intimate conditions as with Miss R. But if we were to accept Dr. Andrew's hypothesis, we should have to admit the following as an explanation of these three cases; that; notwithstanding in each of these cases there had been close and continuous exposure to a known focus i and source of the infective organism of tubercle, yet each of them acquired this organism, not from this known source with which they were in such intimate contact, but from an "independent " source of which we have no knowledge whatever.'. 'Perhaps you will allow me: to:give you two more specimens of the " highly inconclusive" evidence found in this report.
In 1862, a servant came hame to her mother (a widow, with three sons and two daughters, all grown up, father dead of epithelioma), suffering from phthisis. The house; consisting of two rooms and an attic, and lying under, the braw of $\mathrm{a}$ hill on its northern aspect; : Was ill ventilated and wonse lighted. By the end of 1868 , the only survivor of this family, sho being still alive and healthy; was a thin delieate girl, who took fittle or $\$$ o part in the nursing. They all died of phthisis, the mother dying jast, between 50 and 60 years old.

A: young man, of the Indian Navy, came home, suffering from phthisis. In a few months, two of his sisters were taken with the same complaint, and died. A third sister married, and soon afterwards died of the same complaint. The young man also died. Tater on, the father was similarly aftlicted, and died. After his death; the widow became phthisical, and died also. I should think four years covered the whole outbreak-that is, from the arrival of the son from India. The father was originally a very healthy strong man, and all the children healthy up to about 20 or 21 , or even later. I had known them all from infancy. One sister still lives; and is, now between 40 and 50 .

I will ask one more question with regard to these cases. "If evidence of this kind is "highly inconclusive," what would be "? conclusive" evidence? There has been an outcry for clinical evidence; here it is. How can clinical evidence be more forcible? Experimental evidence we possess in abundance.

Dr. Andrew uses, as an argument against communication, the lepgth of time that is reported to have elapsed, in some cases, between the period of exposure to infection and the recognised manifestation of the disease ; but, in the cases recorded in the Report of the Collective Investigation Committee, the period of fatal termination of the disease is mentioned in many, but it would have been exceedingly difficult nay, almost impossible- to fix the time of the first manifestations of disease:

Every experienced physician must have had numerous occasions of ohserving the great resistance which some constitutions seem to offer to the infective action of the organism of tubercle, and how, in others, it seems quietly to diffuse itself widely through the lung before it gives riso to well marked and recognisable physical signs. I am sure I have Iseen many illustrations of both these statements. A young patient will come before you, with some dyspnoea, cough, emaciation, and a highish temperature, but with few definite physical signs; perhaps nothing beyond some slightly diminished expansion of one side, and diffused enfeeblement of vesicular murmur, and here and there patches. of whiffing and harsh respiration. Inquine into his history; you will find he has been out of health for six or eight months, has been treated for dyspepsia, for anæmia, for averwork, has been examined, again and again, by most competent medical men, who have detected no physical signs of phthisis. Now; a ease of this kind teaches us two things: 1 , that the bacillus may gain access to a lung and do extensive and widely diffused mischief there long before the development of readily recognisable physical signs ; and 2, that, supposing such a case to be due, as I believe it may be, to communication, the long lapse of time between the inception of the infective organism and the manifestation of the symptoms renders the detection of the source of infection extremely difficult, if not impossible. Moreover, familiar as we all are with the great diversity in the course and duration of phthisis in different persons, from acute cases of a few weeks to chronic cases of many years, it seems most improbable that it has any definite incubation-period; and this argument of $\mathrm{Dr}$. Andrew therefore appears to me to have no force.

We must not build up hypothetical estimates of a disease like phthisis on the grounds of foreed and fancied analogies ; but we must regard and study phthisis as phthisis, with the help of demonstrated facts, and we must not be surprised that phthisis should have a lifehistory of its own.

Dr. Ransome states that one-half of the mortality in this conntry between the ages of 25 and 35 is due.to consumption. ${ }^{1}$. Dr. Ransome, as well as Dr. Andrew, do not admit hereditary influence to be anything more than a predisposing cause; they both show that phthisis is independent of climate and occupation, though these may have a predisposing influence; they both reject the proposition that mal-nutrition can act as an exciting cause; there is any amount of evidence accumulated that previous chest-disease cannot, of itself excite phthisis ; and of all forms. of chest-disease, pleuritis, followed by adhesions; is the most potent of predisposing ohest-affections, and the influence of adhesive pleuritis, in leading to the retention of germs once admitted into the lungs, by diminishing the power of expiration, is obvious.

1 In a valuable and suggestive lecture on "The Limits of the Infectiveness of Tubercle." 
Surely, then, we must look for some subtle mode of communication from person to person to account for the wide and general diffusion of this malady; for its especial prevalence when masses of human beings are crowded together in towns, in workshops, in prisons, barricks, and convents, and in overpopulated dwellings; conditions and modes of life which directly favour the spread of disease by communication ; while it is absent or rare wherever the population is sparse and scattered, and where extension by communication would bedifficult.

The appeal to elinical evidence, in the present state of our knowledge of the nature of pulmonary consumption, can only furnish proof of the degree of communicability, and the laws which govern it ; and, were it only one tithe of what it is, it would be sufficient to support the fact of communication. For it is now almost universally admitted that the exciting cause of phthisis is in most cases inoperative unless it encounters certain predisposing causes.

Let us take Dr. Andrew's own facts from the City of London Hospital for Diseases of the Chest.

Of 12 resident medical officers, 1 died of very rapid phthisis, before he had been in the hospital a year. From what local "independent" non-parasitic source did he, I would ask Dr. Andrew, acquire the bacillus? If there existed such a source in the hospital itself, surely it was a most unfit place for pulmonary invalids.

Of 3 secretaries, one was "delicate" at the time he took office, and "eventually died of some chest-disease."

Of 255 nurses, sisters, and female servants, one nurse died in the hospital of phthisis, and 33 -about 13 per cent.-left on account of illness. " Some, but certainly not all, were phthisical."

A porter and a dispenser died of phthisis.

Of 51 clinical assistants, "I know," writes the secretary, "that 2 or 3 have become phthisical, but I have not been able to learn the history of a sufficient number to draw any conclusion."

Surely these facts are perfectly consistent with the view that phthisis is spread by communication. I must again insist that it is not necessary to discuss the question whether phthisis is highly contagious under ordinary conditions of life, in this country; we know that it is not.

But the question which presses for decision in the etiology of phthisis is this : is not phthisis always spread by communication, direct or indirect, from person to person ; if it be not so spread, how is it spread? Dr. Andrew has been driven to imagine an independently existing bacillus of non-parasitic origin, of the presence of which amongst us there is not a shadow of proof.

It has been said that, even if phthisis be spread by communication, we ought to conceal the fact from the public, and that it would be calamitous if it were to become generally known. I cannot admit the justness or propriety of this view. What has been the action of the medical profession towards the public, of late years, in regard to preventable and communicable diseases? Have we not been doing everything that was in our power to rouse and alarm them out of their in difference? and shall we hesitate now to declare what we may discover to be the truth with respect to a disease which kills one-half of those who die in this country between 25 and 35 years of age ? With regard to the cause of this wholesale destruction of life at its very prime; cannot believe that this would be either sound morality, sound charity, or sound sens?

In conclusion, let me call your attention to one aspect, and that a practical one, of this argument. If tubercular consumption is always spread by communication from person to person, directly or indirectly, this fact brings this fearfully fatal malady more completely within the class of preventable diseases, and therefore more thoroughly within the scope of preventive medicine. So far, then, from being a depressing view, it is the most hopeful that can be taken of pulmonary consumption; and with this remark I must bring this fragmentary paper to a close. I have only been able, as I said at the commencement, to touch on a few points in the etiology of phthisis; and my chief object has been to induce you to think over the subject of the communicability of phthisis, without prejudice, from the new points of view, which our new knowledge as to the nature of the disease affords.

I have not been able, I regret to say, altogether to avoid a tone which, I am afraid, may have appeared somewhat controversial and a little personal. But it was impossible to quote recent arguments without mentioning their authors; and as I believed some of them to be erroneous, and as standing in the way of sound views as to the etiology of phthisis, I have thought it best to say so frankly and openly.

I am sure those gentlemen whose opinions and arguments I have endeavoured to controvert will accept my criticisms in good part, and will be as glad as I shall be if, by any chance, they lead us any nearer the truth.
REMARKS ON THE TREATMENT OF STRANGULATED HERNIA, FOUNDED ON TWO CASES OF FALSE

ANUS AFTER HERNIOTOMY, IN WHICH THE

"SPUR" WAS REMOVED BY DUPUYTREN'S

ENTEROTOME, AND THE OPENING

CLOSED BY SUTURE.

BY HOWARD MARSH, F.R.C.S., Senior Assistant-Surgeon to St. Bartholomew's Hospital.

CASE I.-Last summer, John R., aged 33, was admitted into St. Bartholomew's Hospital with a large strangulated inguinal hernia. As taxis failed, and I was unable otherwise to return the intestine, I opened the sac. The gut was nearly black, and the different coils were adherent, and formed a large globular mass, which I was afraid to unravel. I therefore stitched the bowel to the margins of the wound, and opened it. The patient quickly recovered; but, two months later, the opening showed no tendency to close, and no fæces were passed per anum. The upper and lower ends of the gut could be easily made out. Dupuytren's enterotome was readily applied, and the blades were partially closed, so that the spur was compressed, but not crushed. Subsequently, the screw was turned a little each day, till on the fourth day the blades were in contact. The instrument spontaneouely slipped out of the fistula on the sixth day. Four days later, the spur was found to be much reduced, but still to form a considerable projection into the interior of the gut. Later, the enterotome was again applied, and screwed up more tightly than on the previous occasion. During the night, the patient felt sick, and complained of considerable abdominal pain, and next day the abdomen was slightly tympanitic. These symptoms, however, subsided, and the enterotome fell off in four days. The spur could now no longer be felt. In the next month, although the external wound contracted, no fæces were passed per anum. I therefore determined to close the fistula. The patient was placed on low diet, and fed almost entirely by enemata for four days. On proceeding to operate, I found the intestine adherent merely to the edges of the external wound, so that, when this connection was scparated, the gut was quite free within the sac. The intestinal fistula was closed by Lembert's method, the bowel returned into the abdominal cavity, and the edges of the external wound were brought together. The patient recovered without any drawback.

CASE II.-Mr. Savory operated on Emma C., aged 54, in February 1884, for femoral hernia. Finding the intestine gangrenous, he opened it in situ. As, four months later, all the fæces escaped through the fistula, and as a prominent "spur" could be felt between the upper and lower ends of the gut, Mr. Savory arranged to apply a modified form of Dupuytren's enterotome, but on going out of town, in vacation time. he left the case in my hands. I applied the enterotome just firmly enough to have a secure hold of the spur, and gradually tightened it. The instrument came away on the fifth day, bringing with it the sphacelated remains of the spur between its blades. Ten days later, as some of the spar could be still felt, the enterotome was again put on. It came away on the seventh day. No spur could now be detected. Two months later, though the external opening had contracted, no fæces passed per anum. I therefore proceeded to close the fistula. Finding the intestine extensively adherent within the sac, I detached only so much as enabled me to bring its edges together. When this had been done, the external wound was closed. Three days later, fæcal discharge occurred through the wound ; but this, which was never large in amount, gradually diminished, and ceased in about a month. The patient left the hospital wearing a truss, to prevent bulging to the scar. Her bowels acted without trouble after the operation.

REMARKs. - The progress of surgery has been great in the last twenty years, but it has been irregular. In some directions there has been a rapid advance ; in others, matters have been at a comparative standstill. The difference has been due, among other causes, to the fact that, where the ground has been new, as in some of the special branches, the course has been open, while along the old lines of practice the tyranny of tradition and routine can only be slowly shaken off. This is well seen in abdominal surgery. In ovariotomy, during which the abdomen is opened, adhesions are broken down, the viscera handled, perhaps a hole accidentally made in the intestine is sewn up, and the peritoneum is thoroughly sponged out, sereral 